\title{
CARACTERÍSTICAS ESTRUTURAIS DE CULTIVARES DIPLÓIDES E TETRAPLÓIDES DE AZEVÉM
}

\author{
STRUCTURAL CHARACTERISTIC OF DIPLOID AND TETRAPLOID RYEGRASS \\ CULTIVARS
}

\author{
Lucas Vargas OLIVEIRA ${ }^{1}$; Otoniel Geter Lauz FERREIRA²; \\ Carlos Eduardo da Silva PEDROSO ${ }^{3}$; Olmar Antônio Denardin COSTA ${ }^{1}$; \\ Luis Alberto Griffith ALONZO'
}

1. Programa de Pós-Graduação em Zootecnia, Faculdade de Agronomia Eliseu Maciel, Universidade Federal de Pelotas, Pelotas, RS, Brasil. lvoliveira.agro@gmail.com; 2. Professor Adjunto, Departamento de Zootecnia, FAEM, UFPEL, Pelotas, RS, Brasil. oglferreira@gmail.com; 3. Professor Adjunto, Departamento de Fitotecnia, FAEM, UFPEL, Pelotas, RS, Brasil

RESUMO: O objetivo do estudo foi determinar, em casa de vegetação, as características estruturais de cultivares de azevém diplóides e tetraplóides, em regime de corte. Os tratamentos constaram de três cultivares diploides [Comum-RS (Lolium multiflorum), Pronto ${ }^{\circledR}$ (L. multiflorum var. westerwoldicum) e Conquest ${ }^{\circledR}$ (L. multiflorum var. italicum)]; e quatro tetraploides [INIA $\operatorname{Titan}^{\circledR}$ (L. multiflorum var. italicum), Winter Star ${ }^{\circledR}$ (L. multiflorum var. westerwoldicum), KLM $138^{\circledR}$ (L. multiflorum var. italicum) e Banquet II $^{\circledR}$ (L. perenne)], alocados em delineamento completamente ao acaso com seis repetições. As cultivares foram semeadas na densidade de 10 sementes vaso ${ }^{-1}$ de $2500 \mathrm{~g}$ de solo, com correção e fertilização realizada em dose única antes da semeadura. Quando as plantas atingiram $20 \mathrm{~cm}$ de altura foi realizado o primeiro corte, para dar condições ao adequado estabelecimento, enquanto os demais foram realizados quando era atingida altura média de $15 \mathrm{~cm}$, deixando-se sempre resíduo de $7 \mathrm{~cm}$. Por análise de variância e comparação de médias pelo teste de Tukey $(\mathrm{P}<0,05)$, foram analisadas as variáveis estruturais: Comprimento final da folha, número de folhas vivas por perfilho, densidade populacional de perfilhos, comprimento da planta e relação folha:colmo, avaliadas no dia de cada corte, momentos antes da execução deste. As cultivares Comum-RS, INIA Titan ${ }^{\circledR}$,

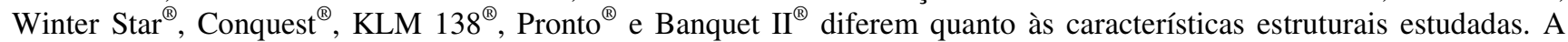
cultivar Banquet $\mathrm{II}^{\circledR}$ apresenta as melhores características estruturais, todavia as cultivares Winter Star ${ }^{\circledR}$, Conquest ${ }^{\circledR}$ e KLM $138^{\circledR}$ também apresentam estrutura adequada ao pastejo durante todo seu ciclo, enquanto Pronto ${ }^{\circledR}$ e Comum-RS, ao final do ciclo, têm a acessibilidade das folhas comprometida.

PALAVRAS-CHAVE: Italicum. Lolium multiflorum. Lolium perene. Westerwoldicum

\section{INTRODUÇÃO}

As pastagens naturais no Estado do Rio Grande do Sul que são peculiares a altitude, clima e ao solo de cada região, são compostas por espécies herbáceas de ciclos estival e hibernal, compondo aproximadamente cerca de 400 gramíneas e 150 leguminosas (BOLDRINI, 1997). No entanto, as espécies estivais predominam nestas pastagens, as quais passam por uma estacionalidade produtiva no outono-inverno, quando ocorre estabilização do crescimento das plantas, devido ao decréscimo das temperaturas e luminosidade neste período frio. Com isso, as gramíneas anuais de estação fria podem ser uma alternativa de produção de forragem para suprir a deficiência alimentar dos animais no outono-inverno, época de reduzida produção animal.

Dentre os recursos forrageiros utilizados neste período, o azevém anual (Lolium multiflorum Lam.) é responsável pela maior área plantada no Rio Grande do Sul, especialmente por seu potencial produtivo e ser adaptado às condições ambientais desse Estado (CONFORTIN, 2009). O azevém, anual ou perene, existe na natureza como planta diploide $(2 \mathrm{n}=2 \mathrm{x}=14$ cromossomos), havendo, no entanto, cultivares tetraploides $(2 \mathrm{n}=4 \mathrm{x}=28$ cromossomos) originadas pelo melhoramento genético vegetal através da técnica de duplicação cromossômica. Plantas de azevém tetraploide apresentam folhas mais largas e de coloração mais escura, menor número de perfilhos, mas de maior tamanho, alta produção total de massa de forragem, ciclo vegetativo mais longo, menor conteúdo de matéria seca e sementes maiores (FARINATTI et al., 2006). Além disso, apresentam aumento do tamanho das células e maior relação conteúdo $\mathrm{x}$ parede celular elevando os teores de carboidratos solúveis, proteínas e lipídios (SMITH et al., 2001; NAIR, 2004).

Em uma pastagem em crescimento vegetativo, onde aparentemente somente folhas estejam sendo produzidas, a morfogênese da planta pode ser descrita por características morfogênicas e estruturais (LEMAIRE; CHAPMAN, 1996). As estruturais são derivadas da combinação das morfogênicas e determinam o ritmo de crescimento 
e desenvolvimento de uma gramínea, afetando, em última instância o processo de pastejo (CAUDURO, 2005). Nos últimos anos, novas cultivares de azevém tem sido lançadas no mercado Sul Brasileiro, tais como: Pronto ${ }^{\circledR}($ L. multiflorum var. westerwoldicum), Conquest ${ }^{\circledR}$ (L. multiflorum var. italicum); Winter $\mathrm{Star}^{\circledR}$ (L. multiflorum var. westerwoldicum), KLM $138^{\circledR}$ (L. multiflorum var. italicum) e Banquet $\mathrm{II}^{\circledR}$ (L. perenne), entre outras. Todavia, as informações sobre estas referem-se à produção, qualidade de forragem e comprimento de ciclo (Mittelmman, 2004; Flores, 2008 e Tonetto, 2009), sem um maior detalhamento sobre características da planta com marcado efeito sobre o comportamento dos animais em pastejo, como as características estruturais da pastagem (Lemaire e Chapmann, 1996, Cruz e Boval, 2000 e Freitas, 2000). Deste modo, o objetivo deste estudo foi caracterizar a estrutura de cultivares de azevém diploides e tetraploides para auxiliar o processo de escolha e seleção dos genótipos.

\section{MATERIAL E MÉTODOS}

$\mathrm{O}$ experimento foi realizado em casa de vegetação pertencente à Faculdade de Agronomia Eliseu Maciel, Universidade Federal de Pelotas, campus Capão do Leão (31 $45^{\prime} 48^{\prime \prime}$ S e $\left.52^{\circ} 29^{\prime} 02^{\prime \prime} \mathrm{W}\right)$, RS, em um período experimental de 225 dias (06/06/2011 a 17/01/2012). Os tratamentos constaram de três cultivares diploides, Comum-RS (Lolium multiflorum), Pronto ${ }^{\circledR}$ (L. multiflorum var. westerwoldicum) e Conquest ${ }^{\circledR}$ (L. multiflorum var. italicum); e quatro tetraploides, INIA $\operatorname{Titan}^{\circledR}(L$. multiflorum var. italicum), Winter $\operatorname{Star}^{\circledR}$ (L. multiflorum var. westerwoldicum), KLM $138^{\circledR}(L$. multiflorum var. italicum) e Banquet $\mathrm{II}^{\circledR}(L$. perenne). As cultivares foram semeadas em 06/06/2011 na densidade de 10 sementes vaso $^{-1}$ de $2500 \mathrm{~g}$ de solo, com as seguintes características químicas: $\mathrm{pH}_{(\mathrm{H} 2 \mathrm{O})}$ : 5 ; Índice SMP: 6,2; Matéria orgânica (\%): 1,8; Argila (\%): 20; CTC $\left(\mathrm{cmol}_{\mathrm{c}} \mathrm{dm}^{-3}\right)$ : 8; $\mathrm{P}\left(\mathrm{mg} \mathrm{dm}^{-3}\right): 12,5$ e $\mathrm{K}\left(\mathrm{mg} \mathrm{dm}^{-3}\right): 62$. O solo foi adubado em dose única antes da semeadura com $4,62 \mathrm{~g}$ de calcário e $0,137 \mathrm{~g}$ da fórmula $10-30-10$ por vaso, conforme recomendação da Sociedade Brasileira de Ciência do Solo (2004) para gramíneas forrageiras anuais de estação fria. Foram utilizados seis vasos por cultivar, constituindo um experimento completamente ao acaso com sete tratamentos e seis repetições.

Por ocasião do aparecimento da primeira folha completamente expandida foi realizado o raleio das plantas, permanecendo três por vaso. Após o surgimento do perfilho secundário, foi marcado com fio colorido o perfilho a ser avaliado (perfilho primário), representativo do vaso, utilizando-se a técnica dos "perfilhos marcados" (CARRÈRE et al., 1997).

Duas vezes por semana foram avaliadas as características estruturais: comprimento final da folha, número de folhas vivas por perfilho, densidade populacional de perfilhos, comprimento da planta (mensurado do substrato até a extremidade da folha mais alta com a planta esticada) e relação folha:colmo.

Quando as plantas atingiram $20 \mathrm{~cm}$ de altura foi realizado o primeiro corte, para dar condições ao adequado estabelecimento das mesmas, enquanto os demais cortes foram realizados quando era atingida altura média de $15 \mathrm{~cm}$ (FREITAS, 2003; PEDROSO et al. 2005), deixando-se sempre resíduo de $7 \mathrm{~cm}$ (MEDEIROS; NABINGER, 2001). Momentos antes do corte, procedia-se uma das avaliações semanais das características estruturais. Para determinar a relação folha:colmo, o material colhido era separado nas frações folha e colmo, e seco a $65^{\circ} \mathrm{C}$ por 72 horas em estufa de circulação forçada de ar. Os resultados, médias de todos os cortes, foram analisados através de análise de variância e teste de comparação de médias (Tukey a $5 \%$ de probabilidade).

Em 05/10, 04/11 e 10/11/2011 as cultivares Comum-RS, Pronto ${ }^{\circledR}$ e Winter Star $^{\circledR}$ entraram em estádio reprodutivo não sendo mais avaliadas. As demais cultivares permaneceram em estádio vegetativo até o encerramento do experimento (17/01/2012).

\section{RESULTADOS E DISCUSSÃO}

Para o comprimento final de folha (CFF), as cultivares Banquet $\mathrm{II}^{\circledR}$ e Conquest ${ }^{\circledR}$ diferenciaram-se significativamente $\quad(\mathrm{P}<0,0001) \quad$ dos demais, apresentando os maiores valores (Tabela 1). Conforme Silveira (2006), alguns fatores que apresentam influência sobre o CFF são o comprimento da bainha, o nível de inserção da folha e o tipo de perfilho. Para a cultivar Banquet $\mathrm{II}^{\circledR}$, o valor elevado de CFF ocorreu em consequência da altura de corte utilizada. Como a cultivar apresenta hábito de crescimento prostrado, necessitou de 88 dias de crescimento para alcançar a altura de corte, sofrendo apenas dois cortes (Tabela 1). Esse fato proporcionou que maior número de folhas de inserção intermediária do perfilho tivesse sua expansão completa, assim, o predomínio de folhas nesse nível de inserção influenciou o CFF. Segundo Gomide e Gomide (2000), folhas em nível de inserção intermediária têm maior dimensão pelo 
maior trajeto a percorrer dentro do pseudocolmo. Mesmo não sendo mensurada a altura da bainha, essas visivelmente foram superiores em tamanho, resultando em maior comprimento de folhas. De acordo com Skinner e Nelson (1995), com o crescimento do pseudocolmo, as folhas subsequentes têm um período de emergência mais longo, alcançando assim comprimentos maiores. $\mathrm{Na}$ cultivar Conquest $^{\circledR}$, o longo intervalo de tempo entre cortes $(32$ dias) pode ter influenciado o comprimento da bainha, que quanto maior, maior a multiplicação celular (DAVIES, 1989) e, consequentemente, maior tamanho da lâmina (DURU; DUCROCQ, 2000). Resultados semelhantes foram encontrados por PONTES et al. (2003), EGGERS et al. (2004) e CAUDURO et al. (2006), que nas maiores bainhas proporcionadas por menores intensidades de desfolha, também obtiveram maior $\mathrm{CFF}$.

Tabela 1. Número de cortes e médias do comprimento final da folha (CFF), número de folhas vivas por perfilho (NFVP), densidade populacional de perfilhos (DP), comprimento da planta (CP) e relação folha:colmo $(\mathrm{F} / \mathrm{C})$ de cultivares diploides e tetraploides de azevém.

\begin{tabular}{ccccccc}
\hline Cultivares & Número & \multicolumn{5}{c}{ Características estruturais } \\
\cline { 3 - 6 } & de cortes & $\begin{array}{c}\text { CFF } \\
(\mathrm{cm})\end{array}$ & $\begin{array}{c}\text { NFVP } \\
\left(\mathrm{n}^{\mathbf{o}}\right)\end{array}$ & $\begin{array}{c}\text { DP } \\
\left(\mathrm{n}^{\mathbf{o}} \text { perf./pl. }\right)\end{array}$ & $\begin{array}{c}\mathrm{CP} \\
(\mathrm{cm})\end{array}$ & F/C \\
\hline Banquet II $^{\circledR}$ & 2 & $11,4626 \mathrm{a}$ & $5,3333 \mathrm{a}$ & $34,750 \mathrm{a}$ & $24,950 \mathrm{a}$ & - \\
Conquest $^{\circledR}$ & 5 & $9,4880 \mathrm{a}$ & $5,4000 \mathrm{a}$ & $22,667 \mathrm{bc}$ & $20,490 \mathrm{~b}$ & - \\
Comum - RS $^{\circledR}$ & 4 & $7,4760 \mathrm{~b}$ & $4,7917 \mathrm{ab}$ & $25,583 \mathrm{ab}$ & $22,258 \mathrm{ab}$ & $19,55 \mathrm{~b}$ \\
Winter Star $^{\circledR}$ & 5 & $7,1024 \mathrm{~b}$ & $4,5667 \mathrm{ab}$ & $20,900 \mathrm{bc}$ & $19,967 \mathrm{~b}$ & $122,72 \mathrm{a}$ \\
KLM 138 $^{\circledR}$ & 6 & $7,0440 \mathrm{~b}$ & $4,5556 \mathrm{ab}$ & $18,417 \mathrm{bc}$ & $19,625 \mathrm{~b}$ & - \\
Pronto $^{\circledR}$ & 10 & $3,6272 \mathrm{c}$ & $4,4167 \mathrm{ab}$ & $15,650 \mathrm{bc}$ & $20,005 \mathrm{~b}$ & $19,27 \mathrm{~b}$ \\
INIA Titan $^{\circledR}$ & 11 & $4,3956 \mathrm{c}$ & $3,6061 \mathrm{~b}$ & $14,333 \mathrm{c}$ & $18,702 \mathrm{~b}$ & - \\
\hline
\end{tabular}

*Médias seguidas da mesma letra na coluna, não diferem pelo teste de Tukey $(\alpha=0,05)$.

Os menores valores de CFF foram encontrados nas cultivares INIA Titan $^{\circledR}$ e Pronto ${ }^{\circledR}$ (Tabela 1), resultados que se devem ao menor tempo que as folhas tinham para crescer, tendo em vista o maior número de desfolhações proporcionado pela intensa rebrotação das mesmas, que chegavam rapidamente à altura de corte. De modo semelhante, PEDROSO et al. (2009), trabalhando com milheto sob pastejo rotativo, associaram o menor comprimento final da lâmina ao menor tempo que estas tinham para crescer. $\mathrm{O}$ menor CFF, segundo Lemaire e Chapman (1996), é explicado pelo processo de adaptação da planta à maior frequência e intensidade de desfolhação, pela sua característica vegetal de plasticidade fenotípica, sendo assim considerada uma estratégia morfológica de escape da planta ao pastejo.

Quanto ao número de folhas vivas por perfilho $(\mathrm{NFVP})$, houve diferença $(\mathrm{P}<0,0009)$ entre as cultivares, obtendo os maiores valores para Banquet II $^{\circledR}$ e Conquest ${ }^{\circledR}$, e o menor para a cultivar INIA Titan $^{\circledR}$ (Tabela 1). O NFVP é uma constante genotípica (Davies, 1988). Sua estabilização, bem como do número de perfilhos por planta, constituise em índice objetivo para orientar o manejo de plantas forrageiras com vistas a maximizar a eficiência de colheita da forragem, prevenindo perdas de folhas por senescência ou morte (GOMIDE, 2007). O maior valor encontrado em
Banquet II ${ }^{\circledR}$ deve-se a forte correlação desta característica estrutural com as características morfogênicas taxa de surgimento de folhas e tempo para o aparecimento de duas folhas consecutivas (filocrono), uma vez que com maior número de folhas surgidas, aliada ao menor tempo de surgimento, mantêm-se um maior número de folhas vivas por perfilho. Na cultivar Conquest, o maior NFVP está correlacionado com a característica morfogênica tempo de vida das folhas, porém, neste caso, com maior intervalo entre cortes (32 dias), em relação aos demais. Isto ocasionou um período maior de sobrevivência dos perfilhos, que devido a menos desfolhações, levaram a uma quantidade expressiva de folhas vivas. Elevado número de folhas vivas é característica estrutural desejável, pois indica acentuada capacidade do pasto em armazenar forragem verde (PEDROSO et al. 2009). Na cultivar INIA Titan $^{\circledR}$, o menor valor de NFVP pode ser explicado pelo grande número de desfolhações sofrido pelo cultivar (Tabela 1), que devido à característica de rápida rebrotação, chegava à altura de corte preconizada $(15 \mathrm{~cm})$ ligeiramente.

A densidade de perfilhos (DP) apresentou diferença $(\mathrm{P}<0,0001)$ entre as cultivares, tendo $\mathrm{O}$ maior e menor valor as cultivares Banquet $\mathrm{II}^{\circledR} \mathrm{e}$ INIA $\operatorname{Titan}^{\circledR}$, respectivamente (Tabela 1). O denso perfilhamento obtido por Banquet II $^{\circledR}$ está, provavelmente, relacionado com a taxa de 
aparecimento de folhas. Isto porque nas axilas das folhas existem gemas, as quais podem ser ativadas pela luminosidade, desde que a planta esteja adequadamente nutrida (NABINGER; PONTES, 2001). Este momento é conhecido na literatura como site filling (ocupação de sítios), no qual ocorre sincronismo entre desenvolvimento das folhas e perfilhamento (DAVIES, 1974). Como o presente trabalho foi conduzido em ambiente protegido, com solo adubado de acordo com a necessidade das plantas, a luminosidade ativou um elevado número de gemas, permitindo que o potencial de perfilhamento deste cultivar fosse explorado. Normalmente espécies perenes, como Banquet II ${ }^{\circledR}$, possuem número maior de perfilhos quando comparadas às espécies anuais. Como exemplo, Davies (1988) encontrou 10.000 perfilhos $/ \mathrm{m}^{2}$ em pastagem com $L$. perenne, valor elevado comparado a Pontes (2001), que encontrou para L. multiflorum 349,9 perfilhos $/ \mathrm{m}^{2}$ durante o período vegetativo. No presente estudo, mesmo com o menor número de desfolhações, a cultivar Banquet II $^{\circledR}$ apresentou maior DP e perfilhos maiores, medida obtida através do comprimento das plantas (Tabela 1). A menor DP apresentada por INIA Titan $^{\circledR}$ se deve ao grande número de cortes efetuados nesse cultivar, que provavelmente afetou negativamente a taxa de surgimento de folhas. Segundo Davies (1974), a DP praticamente não é afetada por uma desfolhação que remova apenas duas a três folhas por perfilho, mas é diminuída em cerca de 15 a $20 \%$ quando todas as folhas de um perfilho são removidas, fato que demonstra intensa força de demanda dos meristemas foliares da cultivar por assimilados após os cortes. Sendo assim, a DP é passível de ser utilizada no processo de seleção de cultivares, tornando-o mais preciso no que se refere à descrição da adaptação da planta ao ambiente e ao pastejo.

Para o comprimento da planta (CP), a cultivar Banquet II ${ }^{\circledast}$ obteve o maior valor, diferindo $(\mathrm{P}<0,0002)$ dos demais, a exceção da cultivar Comum-RS (tabela 1). A superioridade da cultivar Banquet $\mathrm{II}^{\circledR}$, além de ser devido a maior CFF, também ocorreu em função da altura de corte utilizada. Como a cultivar apresenta hábito de crescimento prostrado, levou muito tempo para atingir a altura de corte, fato que permitiu maior período de crescimento e consequente incremento do CP. Na cultivar Comum-RS, o maior valor é devido ao alongamento precoce dos entrenós, o qual começou a ocorrer após o segundo corte, aos 112 dias após a semeadura.

$\mathrm{Na}$ relação folha:colmo (F:C) houve diferença $(\mathrm{P}<0,0004)$ entre as cultivares Pronto ${ }^{\circledR}$, Comum-RS e Winter $\mathrm{Star}^{\circledR}$, tendo ocorrido maior valor nesta última. Devido ao ciclo tardio das demais cultivares, o material colhido era composto somente por folhas e, por esse motivo, não foi calculada sua relação F:C. A superioridade da cultivar Winter Star $^{\circledR}$ frente as cultivares Pronto ${ }^{\circledR} \mathrm{e}$ Comum-RS se deve ao fato da mesma ter iniciado o processo de alongamento dos entrenós somente após o penúltimo corte (quarto), sendo a quantidade de colmos pouco expressiva. Mesma tendência de alongamento dos entrenós no final do ciclo foi observada na cultivar Pronto ${ }^{\circledR}$, que mostrou colmos somente nos dois últimos cortes, de um total de dez. Entretanto, nesta cultivar, a quantidade de colmos foi elevada em relação às folhas, o que resultou em baixa relação F:C. Por sua vez, a cultivar ComumRS apresentou colmos após o segundo corte, sendo estes de elevada proporção até o final de seu ciclo (dois cortes seguintes). Deve-se salientar o período produtivo destas três cultivares, que mesmo inferior aos demais, encerraram seus ciclos dentro do período adequado para gramíneas de estação fria. Devido às características genotípicas das cultivares, as mesmas encerraram seu período vegetativo na seguinte ordem: Comum-RS, Pronto ${ }^{\circledR}$ e Winter Star $^{\circledR}$. A relação $F: C$ é uma variável importante na nutrição animal e no manejo das plantas forrageiras. Um dossel com alta relação $\mathrm{F}: \mathrm{C}$ apresenta melhor valor nutritivo e maior facilidade de apreensão da forragem pelo animal em pastejo. Segundo PINTO et al. (1994), alta relação F:C confere a gramínea melhor adaptação ao pastejo ou tolerância ao corte, por representar um momento fenológico em que os meristemas apicais se apresentam mais próximos ao solo, e, portanto, menos vulneráveis à remoção.

\section{CONCLUSÕES}

As cultivares Comum-RS, INIA Titan ${ }^{\circledR}$, Winter $\operatorname{Star}^{\circledR}$, Conquest $^{\circledR}$, KLM $138^{\circledR}$, Pronto $^{\circledR}$ e Banquet II $^{\circledR}$ diferem quanto às características estruturais comprimento final da folha, número de folhas vivas por perfilho, densidade populacional de perfilhos, comprimento da planta e relação folha:colmo.

A cultivar Banquet II $^{\circledR}$ apresenta as melhores características estruturais, todavia as cultivares Winter Star ${ }^{\circledR}$, Conquest ${ }^{\circledR}$ e KLM $138^{\circledR}$ também apresentam estrutura adequada ao pastejo durante todo seu ciclo, enquanto Pronto ${ }^{\circledR}$ e ComumRS, ao final do ciclo, têm a acessibilidade das folhas comprometida. 
AGRADECIMENTOS

Ao $\mathrm{CNPq}$ pelo auxílio financeiro, a COOPLANTIO/Pelotas a a
GOVI/DZ/FAEM/UFPEL pela contribuição na realização deste trabalho.

\begin{abstract}
The main goal was to determine, under defoliation, in greenhouse, ryegrass structural traits of diploid and tetraploid cultivars. Treatments consisted of three diploid cultivars [Comum-RS (Lolium multiflorum), Pronto ${ }^{\circledR}$ (L. multiflorum var. westerwoldicum) and Conquest ${ }^{\circledR}$ (L. multiflorum var. Italicum)], and four tetraploids [INIA Titan ${ }^{\circledR}(\mathrm{L}$.

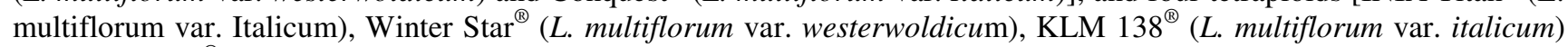
and Banquet $\mathrm{II}^{\circledR}$ (L. perenne)], in a completely randomized design with six replications. Cultivars were sown at a density of 10 seeds pot $^{-1} 2500 \mathrm{~g}$ of soil; correction and fertilization was performed in a single dose before sowing. When plants reached $20 \mathrm{~cm}$ height the first cutting was made, to allow for appropriate establishment. The following cuttings were made when when plants reached $15 \mathrm{~cm}$ average height, always leaving a residue of $7 \mathrm{~cm}$. Data were submitted to analysis of variance and means compared by Tukey test $(\mathrm{P}<0.05)$. Variables evaluated were: Final length leaf, number of life leaves, population tillers density, plant length and leaf/sheath ratio, evaluated on each cut, moments before the execution of this.

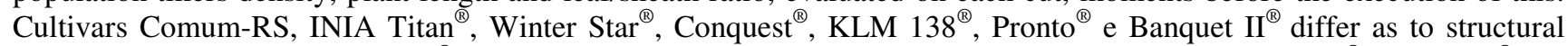
characteristics studed. Banquet II ${ }^{\circledR}$ cultivar presents the best structural features, however the Winter Star ${ }^{\circledR}$, Conquest $^{\circledR}$ and KLM $138^{\circledR}$ cultivars also have adequate structure to grazing throughout your cycle, while Pronto ${ }^{\circledR}$ and Comum-RS, to the end of the cycle, have accessibility leaves compromised.
\end{abstract}

KEYWORDS: Italicum. Lolium multiflorum. Lolium perene. Westerwoldicum

\title{
REFERÊNCIAS
}

BOLDRINI, I. I. Campos do Rio Grande do Sul: Caracterização Fisionômica e Problemática Ocupacional. Boletim do Instituto de Biociências: Ecologia v. 56, p. 1-33. 1997.

CARRÈRE, P.; LOUAULT, F.; SOUSSANA, J. F. Tissue turnover within grass clover mixed swards grazed by sheep. Methodology for calculating growth, senescence and intake fluxes. Journal of Applied Ecology, v. 34, p. 333-348, 1997. http://dx.doi.org/10.2307/2404880

CAUDURO, G. F. Morfogênese e dinâmica de acúmulo de forragem em pastagens de azevém anual manejadas sob intensidades de métodos de pastejo. 2005. 130f. Dissertação (Mestrado) - Programa de PósGraduação em Zootecnia, Faculdade de Agronomia, Universidade Federal do Rio Grande do Sul, Porto Alegre, 2005.

CAUDURO, G. F.; CARVALHO, P. C. F.; BARBOSA, C. M. P.; LUNARDI, R.; NABINGER, C.; GONÇALVES, E. N.; DEVINCENZI, T. Variáveis morfogênicas e estruturais de azevém anual (Lolium multiflorum Lam.) manejado sob diferentes intensidades e métodos de pastejo. Revista Brasileira de Zootecnia, v. 35, n. 4, p. 1298-1307, 2006. http://dx.doi.org/10.1590/S1516-35982006000500007

CONFORTIN, A. C. C. Dinâmica do crescimento do azevém anual submetido a diferentes intensidade de pastejo. 2009. 98p. Dissertação de Mestrado. Universidade Federal de Santa Maria, Santa Maria, RS, 2009.

CRUZ, P.; BOVAL, M. Effect of nitrogen on some morphogenetic traits of temperate and tropical perennial forage grasses. In: Lemaire, G.; Hodgson, J.; Moraes, A. (ed.) Grassland ecophysiology and grazing ecology. Wallingford: CABI Publishing. 2000. p. 151-168. http://dx.doi.org/10.1079/9780851994529.0151

DAVIES, A. Leaf tissue remaining after cutting and regrowth in perennial ryegrass. Journal of Agricultural Science, v. 82, p. 165-172, 1974. http://dx.doi.org/10.1017/S0021859600050334

DAVIES A. The regrowth of grass swards. In: JONES M.B. e LAZEMBY A. (eds.) The physiological basis of production. Chapman and Hall, London. 1988, p. 85-127. 
DAVIES, D. A.; FOTHERGILL, M.; JONES, D. Frequency of stocking rate required on contrasting upland perennial ryegrass pastures continuously grazed to a sward height criterium from May to July. Grass and Forage Science, 1989. v. 44, p. 213-221. http://dx.doi.org/10.1111/j.1365-2494.1989.tb01929.x

DURU, M; DUCROCQ, H. Growth and senescence of the successive grass leaves o a tiller ontogenic development and effect of temperature. Annals of Botany, v. 85, p. 635-643, 2000.

http://dx.doi.org/10.1006/anbo.2000.1116

EGGERS, L.; M.; BOLDRINI, I. I. Phyllochron of Paspalum notatum FL. and Coelorhachis selloana (Hack.) camus in natural pasture. Scientia Agricola, v. 61, n. 4, p. 353- 357, 2004. http://dx.doi.org/10.1590/S010390162004000400001

FARINATTI, L. H. E.; ROCHA, M. G.; POLI, C. H. E. C.; PIRES, C. C; PÖTTER, L.; SILVA, J. H. Desempenho de ovinos recebendo suplementos ou mantidos exclusivamente em pastagem de azevém (Lolium multiflorum Lam.). Revista Brasileira de Zootecnia, v.35, n.2, p.527-534, 2006. http://dx.doi.org/10.1590/S1516-35982006000200027

FLORES, R. A.; AGNOL, M. D.; NABINGER, C.; MONTARDO, D. P. Produção de forragem de populações de azevém anual no estado do Rio Grande do Sul. Revista Brasileira de Zootecnia, v. 37, n. 7, p. 1168-1175, 2008. http://dx.doi.org/10.1590/S1516-35982008000700005

FREITAS, T. M. S. de. Dinâmica da produção de forragem, comportamento ingestivo e produção de ovelhas Ile de France em pastagem de azevém anual (Lolium multiflorum Lam.) em resposta a doses de nitrogênio. 2003. 114f. Dissertação (Mestrado) - Programa de Pós-Graduação em Zootecnia, Faculdade de Agronomia, Universidade Federal do Rio Grande do Sul, Porto Alegre, 2003.

GOMIDE, C. A. M.; GOMIDE, J. A. Morfogênese de cultivares de Panicum maximum Jacq. Revista Brasileira de Zootecnia, v. 29, n. 2, p. 341-348, 2000. http://dx.doi.org/10.1590/S1516-35982000000200004

GOMIDE, C. A. M.; GOMIDE, J. A.; ALEXANDRINO, E. Características estruturais e produção de forragem em pastos de capim-mombaça submetidos a períodos de descanso. Pesquisa Agropecuária Brasileira, v. 42, n. 10, p. 1487-1494, 2007. http://dx.doi.org/10.1590/S0100-204X2007001000017

LEMAIRE, G.; CHAPMAN. D. Tissue flows in grazed plant communities. In: HODGSON, J.; ILLIUS, A.W. (Eds.) The ecology and management of grazing qsystems. Wallingford: CAB International, p. 3-36, 1996.

MEDEIROS, R. B.; NABINGER, C. Rendimento de sementes e forragem de azevém anual em resposta a dose de nitrogênio e regime de corte. Revista Brasileira de Sementes, (Campinas, SP), v. 23, n. 2, p. 145-154, 2001.

MITTELMANN, A.; LÉDO, F. J. S.; POLI, C. H. E. C.; MORAES, C. O. C.; NESKE, M. Z. Avaliação de populações de azevém quanto à produção de forragem. Juiz de Fora: Embrapa Gado de Leite; Bagé: Embrapa Pecuária Sul, 2004b. 12 p. (Embrapa Gado de Leite. Boletim de Pesquisa, 15).

NABINGER, C., PONTES, L. da S. Morfogênese de plantas forrageiras e estrutura do pasto. In: REUNIÃO DA SOCIEDADE BRASILEIRA DE ZOOTECNIA, 38, 2001. Piracicaba. Anais... Piracicaba: SBZ, 2001, p. 755-771.

NAIR, R. Developing tetraploid perennial ryegrass (Lolium perenne L.) populations. New Zealand Journal Agricultural Research. V. 47, p. 45-49. 2004. http://dx.doi.org/10.1080/00288233.2004.9513569

PEDROSO, C. E. S.; MENEZES NETO, D. B.; AFFONSO, A. B.; MONKS, P. L.; ESTEVES, R. M. G.; FERREIRA, O. G. L.; MORAES, P. V. D.; SIEWERDT, L. Preferência de ovinos sob pastejo em azevém anual em diferentes alturas. In: REUNIÃO ANUAL DA SOCIEDADE BRASILEIRA DE ZOOTECNIA, 42, 2005, Goiânia. Anais... 2005, 1 CD-ROM. http://dx.doi.org/10.1590/S1516-35982009000500004 
PEDROSO, C. E. S.; MONKS, P. L.; FERREIRA, O. G. L.; LIMA, L. S.; TAVARES, O. M. Características estruturais de milheto sob pastejo rotativo com diferentes períodos de descanso. Revista Brasileira de Zootecnia, v. 38, n. 5, p. 801-808, 2009.

PINTO, J. C.; GOMIDE, J. A.; MAESTRI, M. Produção de matéria seca e relação folha/caule de gramíneas forrageiras tropicais, cultivadas em vasos, com duas doses de nitrogênio. Revista Brasileira de Zootecnia, v. 23, n. 3, p. 313-326, 1994.

PONTES, L. da S. Dinâmica de crescimento em pastagens de azevém anual (Lolium multiflorum Lam.) manejadas em diferentes alturas. 2001. 102f. Dissertação (Mestrado em Zootecnia) - Universidade Federal do Rio Grande do Sul, 2001.

PONTES, L. S.; NABINGER, C.; CARVALHO, P. C. F.; TRINDADE, J. K.; MONTARDO, D. P.; SANTOS, R. J. Variáveis morfogênicas e estruturais de azevém anual (Lolium multiflorum Lam.) manejado em diferentes alturas. Revista Brasileira de Zootecnia, v. 32, n. 4, p. 814-820, 2003. http://dx.doi.org/10.1590/S151635982003000400005

SILVEIRA, M. C. T. Caracterização morfogênica de oito cultivares do gênero Brachiaria e dois do Gênero Panicum. 91f. 2006. Dissertação (Mestrado) - Programa de Pós-Graduação em Zootecnia, Universidade Federal de Viçosa. Viçosa, MG, 2006.

SKINNER, R. H.; NELSON, C. J. Elongation of the grass leaf and its relationship to the phylochron. Crop Science, v. 34(1), p. 4-10, 1995. http://dx.doi.org/10.2135/cropsci1995.0011183X003500010002x

SMITH, K.; SIMPSON, R.; CULVENOR, M.; HUMPHREYS, M.; PRUD’HOMME M.; ORAM, R. The effects of ploidy and a phenotype conferring a high water soluble carbohydrate concentration on carbohydrate accumulation, nutritive value and morphology of perennial ryegrass (Lolium perenne). Journal of Agricultural Science (Cambridge) v. 136, p. 65-74, 2001. http://dx.doi.org/10.1017/S0021859600008480

SOCIEDADE BRASILEIRA DE CIÊNCIA DO SOLO. COMISSÃO DE QUÍMICA E FERTILIDADE DO SOLO RS/SC (CQFS RS/SC). Manual de adubação e calagem para estados do Rio Grande do Sul e Santa Catarina. SBCS/NRS. 10.ed. Porto Alegre, 2004, 400p.

TONETTO, C. J. Avaliação de genótipos de azevém diploide e tetraploide com manejos distintos de cortes visando duplo propósito. 2009. 53 f. Tese (Doutorado em Agronomia) - Universidade Federal de Santa Maria, 2009. 